\title{
Quantitative evaluation of visual function 12 months after bilateral implantation of a diffractive trifocal IOL
}

\author{
João P. Marques ${ }^{1}$, Andreia M. Rosa ${ }^{1,2}$, Bruno Quendera ${ }^{3,4}$, Fátima Silva ${ }^{3}$, Joaquim Mira ${ }^{1}$, Conceição Lobo ${ }^{1,2}$, \\ Miguel Castelo-Branco ${ }^{2-4}$, Joaquim N. Murta ${ }^{1,2}$ \\ ${ }^{1}$ Department of Ophthalmology, Centro Hospitalar e Universitário de Coimbra (CHUC), Coimbra - Portugal \\ ${ }^{2}$ Faculty of Medicine, University of Coimbra (FMUC), Coimbra - Portugal \\ ${ }^{3}$ Visual Neuroscience Laboratory of the Institute for Biomedical Imaging and Life Sciences (IBILI), University of Coimbra, Coimbra - Portugal \\ ${ }^{4}$ Institute for Nuclear Sciences Applied to Health (ICNAS), University of Coimbra, Coimbra - Portugal
}

\begin{abstract}
Purpose: To quantitatively evaluate visual function 12 months after bilateral implantation of the Physiol FineVision $^{\circledR}$ trifocal intraocular lens (IOL) and to compare these results with those obtained in the first postoperative month.

Methods: In this prospective case series, 20 eyes of 10 consecutive patients were included. Monocular and binocular, uncorrected and corrected visual acuities (distance, near, and intermediate) were measured. Metrovision ${ }^{\circledR}$ was used to test contrast sensitivity under static and dynamic conditions, both in photopic and low-mesopic settings. The same software was used for pupillometry and glare evaluation. Motion, achromatic, and chromatic contrast discrimination were tested using 2 innovative psychophysical tests. A complete ophthalmologic examination was performed preoperatively and at 1, 3, 6, and 12 months postoperatively. Psychophysical tests were performed 1 month after surgery and repeated 12 months postoperatively.

Results: Final distance uncorrected visual acuity (VA) was $0.00 \pm 0.08$ and distance corrected VA was $0.00 \pm 0.05$ logMAR. Distance corrected near VA was $0.00 \pm 0.09$ and distance corrected intermediate VA was $0.00 \pm 0.06$ logMAR. Glare testing, pupillometry, contrast sensitivity, motion, and chromatic and achromatic contrast discrimination did not differ significantly between the first and last visit $(p>0.05)$ or when compared to an age-matched control group ( $p>0.05)$.

Conclusions: The Physiol FineVision ${ }^{\circledR}$ trifocal IOL provided satisfactory full range of vision and quality of vision parameters 12 months after surgery. Visual acuity and psychophysical tests did not vary significantly between the first and last visit.
\end{abstract}

Keywords: Cataract surgery, Multifocal intraocular lens, Trifocal intraocular lens, Visual acuity, Visual function

\section{Introduction}

Spectacle independence has become a goal of workingage cataract patients. Numerous intraocular lens (IOL) optical profiles and surface designs have been developed, aimed at fulfilling patients' rising expectations on visual performance $(1,2)$. Several studies $(2-4)$ have shown that late generation multifocal IOLs provide excellent distance and near visual acuity (VA) as well as functional intermediate vision, despite some inevitable energy loss (5). Multifocal aspheric IOLs with

\section{Accepted: May 20, 2015}

Published online: June 15, 2015

Corresponding author:

João Pedro Marques, MD, MSc

Department of Ophthalmology

Centro Hospitalar e Universitário de Coimbra

Praceta Prof. Mota Pinto

3049 Coimbra, Portugal

marquesjoaopedro@gmail.com a low add were specifically designed to increase the range of focus and thus improve visual quality at intermediate distances (2). Even though this approach has proven successful to some extent (2-4), patients may ultimately be dependent on spectacles for clear intermediate vision (5). This problem is particularly significant in working-age patients, who often perform rapidly alternating far and close-up tasks or sustain long work at near to intermediate distance (6).

Another important drawback of multifocal IOL implantation is the development of photic phenomena such as glare, halos, and a decrease in contrast sensitivity, especially under dim light conditions (4). These can negatively affect daily life activities, limiting the patient's ability to perform them and thus affecting the patient's quality of life (6). Although improvements in IOL design have limited these symptoms in late generation multifocal IOLs, they are still among the most frequent reasons for dissatisfaction after multifocal IOL implantation (7-10).

Recently, a new multifocal model of IOL has been introduced in clinical practice. The PhysIOL FineVision ${ }^{\circledR}$ trifocal IOL (Liège, Belgium) received the Conformité Européenne label in February 2010. In addition to 2 major foci at $0.00 \mathrm{D}$ 
and +3.50 D add power for far and near vision, respectively, the FineVision ${ }^{\circledR}$ trifocal IOL displays a third focus at $+1.75 \mathrm{D}$, pointed at intermediate vision (11). Gatinel and Houbrechts (12) assessed the differences in optical performance of 9 multifocal IOLs using an optical bench and observed a lack of intermediate vision with bifocal IOLs, whereas a distinct peak at the intermediate distance was obvious for the trifocal diffractive IOL (PhysIOL FineVision ${ }^{\circledR}$ ). The few published clinical studies $(5,13-15)$ that describe the outcomes after implantation of this new IOL model have demonstrated that it provides enhanced visual performance at intermediate vision without significantly compromising distance and near VA. Even though contrast sensitivity was evaluated in some of these studies $(5,15)$, it was tested at high luminance values $\left(3.0\right.$ and $\left.5.0 \mathrm{~cd} / \mathrm{m}^{2}\right)$. Low mesopic contrast sensitivity is particularly important when evaluating multifocal IOLs because some advantages of specific IOL designs (namely pupildependent IOL designs) are attenuated by pupil dilation (4). Also, complaints of decreased contrast sensitivity are usually elicited under dim light conditions (i.e., night driving). Since luminance levels for evaluating visual performance under night driving vary between $0.01 \mathrm{~cd} / \mathrm{m}^{2}$ and $1.00 \mathrm{~cd} / \mathrm{m}^{2}$, a low value of luminance $\left(0.08 \mathrm{~cd} / \mathrm{m}^{2}\right)$ is more likely to represent a real-life mesopic scenario (16). There are several other objective measurements of visual function that, to our knowledge, have not been evaluated in the available publications. Motion discrimination, for instance, is of paramount importance while driving, since prolonged driving at a fixed speed (e.g., $100 \mathrm{~km} / \mathrm{h}$ ) may reduce the perceived speed but improve the sensitivity to changes in the prevailing speed (17). Because subjective data alone cannot adequately describe the performance and optical outcomes of a new IOL design, the purpose of this study is to quantitatively evaluate several parameters of visual function using computerized psychophysical tests, 12 months after bilateral implantation of a new aspheric diffractive trifocal IOL, and to compare these results with those obtained in the first postoperative month.

\section{Methods}

\section{Patients}

This prospective case series included 20 eyes of 10 consecutive patients that underwent cataract surgery and bilateral implantation of a new aspheric diffractive trifocal IOL (Physiol FineVision ${ }^{\circledR}$ ). The study was performed in accordance with the ethical standards of the Declaration of Helsinki. Institutional review board approval was obtained and patients signed an informed consent form after receiving a detailed explanation of the possible consequences of participating in the study. Exclusion criteria were $(1) \geq 1.5 \mathrm{D}$ of corneal astigmatism; (2) irregular corneal topography; (3) illiteracy; and (4) history of other ocular comorbidities, such as glaucoma, retinal disease, previous corneal or intraocular surgery, or pupil deformation.

\section{Intraocular lens}

The FineVision ${ }^{\circledR}$ trifocal IOL is a single-piece aspheric diffractive foldable IOL composed of a $25 \%$ hydrophilic acrylic material with a blue-blocking filter (13). The optic combines 2 diffractive structures that are adjusted to offer $\mathrm{a}+3.5 \mathrm{D}$ addition for near and $\mathrm{a}+1.75 \mathrm{D}$ addition for intermediate vision. By varying the height of the diffractive steps (apodization), the amount of light distributed to near, intermediate, and distant foci is adjusted according to pupil size (11). The IOL has a total diameter of $10.75 \mathrm{~mm}$, an optic body diameter of $6.15 \mathrm{~mm}$, and a 5-degree haptic angulation. Additionally, the 4-point haptic design (Fig. 1) minimizes decentration, increases the contact surface, and allows for absorption of the capsular contraction forces, thus preventing its transmission to the optic (11). The power range available is from +10 to +35 D (steps of 0.50 D).

\section{Surgical technique}

Surgeries were performed using topical anesthesia through a $2.75-\mathrm{mm}$ clear corneal incision in the steepest meridian by experienced refractive surgeons. Phacoemulsification was performed using an Infiniti Vision System unit (Alcon, Fort Worth, TX, USA) and was followed by irrigation and aspiration of the cortex and IOL implantation in the capsular bag. All eyes had a 1-week time frame between surgeries and all surgeries were uneventful.

\section{Preoperative and postoperative evaluation}

Preoperative evaluation comprised a complete ophthalmologic examination including manifest refraction, slit-lamp biomicroscopy, topography (Orbscan $\|^{\circledR}$, Bausch \& Lomb, Rochester, NY, USA), specular microscopy, dilated funduscopy and Goldmann applanation tonometry. The Allegro ${ }^{\circledR}$ Biograph device (Wavelight AG, Erlangen, Germany) and the SRK/T formula (18) were used for IOL calculation. The target in the IOL power calculation was plano in all cases included in the study.

A complete ophthalmologic examination was performed $1,3,6$, and 12 months postoperatively. The same independent investigator (J.P.M.) performed all postoperative examinations using the same investigational protocol. Monocular and binocular, uncorrected and corrected visual acuities (distance, near, and intermediate) were assessed in every visit. Distance VA was measured with an Early Treatment Diabetic Retinopathy Study (ETDRS) chart. Intermediate $(70 \mathrm{~cm})$ and near $(40 \mathrm{~cm})$ visual acuities were evaluated with the near ETDRS chart, with an adjustment for intermediate VA, as previously described in other studies from our group (4). All measurements were taken under photopic conditions $\left(80 \mathrm{~cd} / \mathrm{m}^{2}\right)$.

\section{Psychophysical testing}

The psychophysical tests were performed 1 month and 12 months postoperatively. We did not perform it preoperatively due to the influence of cataract in the testing results. We used proprietary software for motion and chromatic and achromatic contrast discrimination testing. For pupillometry, static and dynamic contrast sensitivity, and glare measurements, we used the Vision Monitor ${ }^{\circledR}$ (MonCv3; Metrovision ${ }^{\circledR}$, Pérenchies, France), a software that has already been used in refractive surgery (4) and glaucoma (19). 

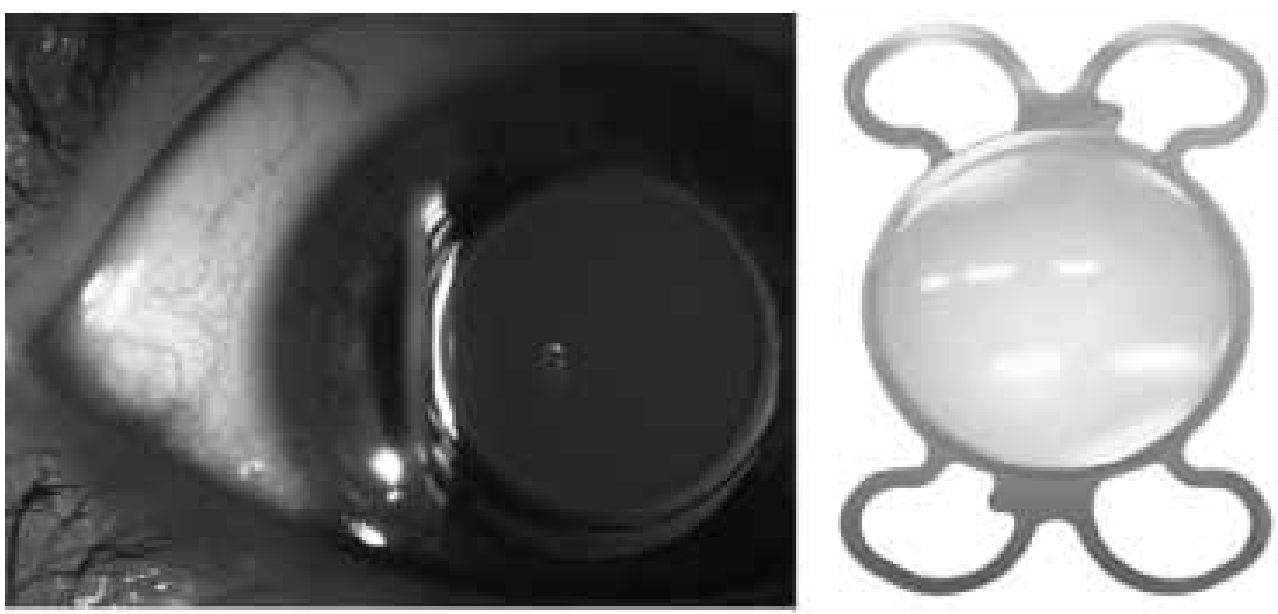

Fig. 1 - FineVision ${ }^{\circledR}$ trifocal intraocular lens (IOL). On the left, a close up view of a perfectly centered Fin-

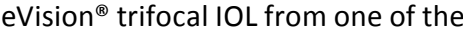
subjects included in our study. The image on the right demonstrates the 4-haptic design of this IOL model and the concentric diffractive rings.

\section{Motion and chromatic and achromatic contrast discrimination}

The examinations took place in a darkened room where subjects completed the tests both monocularly and binocularly, $50 \mathrm{~cm}$ away from the display system. All stimuli were presented on a gamma-corrected 24" LCDIPS monitor (ColorEdge CG243W ${ }^{\oplus}$, Eizo, Japan) with a resolution of $1920 \times$ 1200 pixels and a refresh rate of $60 \mathrm{~Hz}$. Spectral and luminance measurements were accomplished using a spectroradiometer (PR-650 SpectraScan Colorimeter ${ }^{\circledR}$, Photo Research Inc., Chatsworth, PA, USA). We used 3 2AFC (2-alternative forced choice) psychophysical tests that required the comparison and discrimination of a visual feature (motion, achromatic and chromatic contrast) between 2 separated moving single dots (a reference dot and a target dot). During $400 \mathrm{~ms}$ trials, the reference and target dots were simultaneously presented on randomly alternated visual hemifields, moving back and forth along a $2^{\circ}$ pseudorandom linear trajectory (between $0^{\circ}$ and $180^{\circ}$ ). After each trial, the subject gave a verbal response, which the experimenter stored by means of a standard keyboard (due to the subjects' average age and to avoid motor errors). There was no time limit for this response. The visual feature being evaluated was then adjusted in the following trial by using a logarithmic staircase procedure. The tests ended after 6 reversals and a discrimination threshold was calculated using the arithmetic mean of the last 4 reversals. Each test (including chromatic contrast subtests) was repeated 4 times, corresponding to 1 of 4 different meridian/eccentricity pairs (the horizontal meridian $\left[0^{\circ}\right]$ was tested at $7.5^{\circ}$ of eccentricity; the vertical meridian $\left[90^{\circ}\right]$, at $10^{\circ}$; the oblique meridians $\left[45^{\circ}\right.$ and $135^{\circ}$ ], at $15^{\circ}$ of eccentricity). We used 2 squared dots measuring $0.3^{\circ} \times 0.3^{\circ}$ for the motion discrimination test and $0.6^{\circ} \times 0.6^{\circ}$ for both contrast discrimination tests. Fixation on a black central cross (size $1^{\circ}$ ) was present during the whole test (Fig. 2). The background was a $25 \mathrm{~cd} / \mathrm{m}^{2}$ gray for all testing conditions. The subject was asked "Which dot is moving faster?" for motion discrimination test, "Which dot is brighter?" for achromatic contrast discrimination test, or "Which dot has color?" for chromatic contrast discrimination test, and answered either "left/right" (for horizontal meridian) or "up/down" (for vertical and oblique meridians).

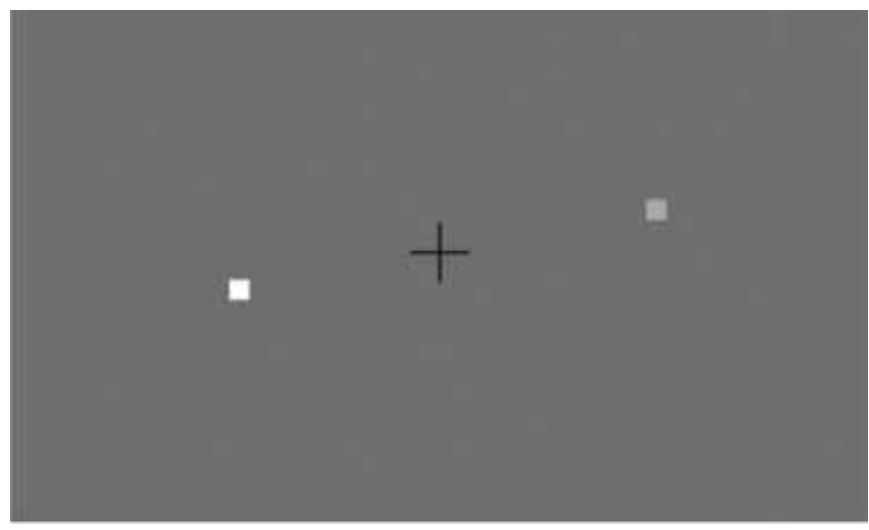

Fig. 2 - Achromatic contrast discrimination testing. Note the black central cross $\left(\right.$ size $\left.1^{\circ}\right)$ which is present during the whole test and the 2 squared moving dots measuring $0.6^{\circ} \times 0.6^{\circ}$. In this test, the 2 square dots move at the same velocity $(5 \% \mathrm{~s})$ and the patient is asked "Which dot is brighter?" The answer should be "left/right" for the horizontal meridian or "up/down" for the vertical and oblique meridians.

All tests began with 2 dots (a reference and a target dot) that presented variable motion/luminance/color and were then adjusted during the test according to the subjects' responses. For achromatic and chromatic tests, reference and target dots moved at the same velocity $\left(5^{\circ} / \mathrm{s}\right)$. For chromatic discrimination tests, we studied 3 different colors divided into subtests, and the reference dot was assigned the same relative coordinates (to the display's maximum white) in the LMS color space (20), LMS color units $(0.4106,0.4108,0.4241)$, giving it a gray, "colorless" appearance. The target dot starting point for the L, M, S-cone subtests was L(0.4732), M(0.5158), $S(0.9)$, respectively. These appeared like a pale red, green, and purple dot, respectively. Luminance cues were further avoided by a matrix of luminance noise around each dot. This matrix was composed of $120.3^{\circ}$ squared dots, with 6 luminance noise levels $\left(30,34,38,42,46\right.$, or $\left.48 \mathrm{~cd} / \mathrm{m}^{2}\right)$, with 2 dots for each luminance noise value; the luminance of each dot randomly changed during the trial (synchronized to the screen refresh rate). 


\section{Static and dynamic contrast sensitivity}

Sinusoidal vertical gratings whose parameters (luminance, contrast, spatial frequency) are automatically controlled by the computer were presented with a very low contrast at first and progressively increasing contrast thereafter. We used static $(0 \mathrm{~Hz})$ and dynamic $(10 \mathrm{~Hz})$ tests, both monocularly and binocularly. Patients were instructed to press a button when detecting the grating bars.

This was performed under photopic (average luminance of the grating is $80 \mathrm{~cd} / \mathrm{m}^{2}$ ) and low mesopic conditions (with the use of specific goggles with 3 log unit filters that bring the average luminance down to $0.08 \mathrm{~cd} / \mathrm{m}^{2}$ ), after a $10 \mathrm{~min}$ period of adaptation. The results were depicted as a curve of contrast sensitivity versus spatial frequency. The response curve was obtained using 6 different spatial frequencies expressed in cycles per degree (cpd) (high to low spatial frequencies: 14.2-7.1-3.4-2.2-1.1-0.6). Spatial contrast sensitivity function was calculated using the following equation: spatial contrast sensitivity function $(\mathrm{dB})=10 \log [(\operatorname{Lmax}+\operatorname{Lmin}) /$ (Lmax - Lmin)], where Lmin is the minimum luminance of the grating and Lmax is its maximum luminance. Contrast sensitivity testing was performed with the best optical correction for the test distance $(2 \mathrm{~m})$.

\section{Pupillometry and glare testing}

The pupillometry program offers automated measurements of the pupil size under controlled illumination conditions $\left(1,10\right.$, and $\left.100 \mathrm{~cd} / \mathrm{m}^{2}\right)$. Images were acquired using near infrared illumination (880 $\mathrm{nm})$ and a high-resolution camera. The pupil contour is automatically outlined in the captured image but the user is able to control for the measurement accuracy in the screen. All the acquired images can be recorded and printed. For visual aptitude under glare, we presented calibrated low luminance (1 and $5 \mathrm{~cd} /$ $\mathrm{m}^{2}$ ) optotypes over a dark background with a lateral high luminance light source (glare source). Tests were performed monocularly. A quantitative score was obtained by counting the number of letters that the patient correctly identified despite diffusion within the eye. The final score was given as a percentage, with $100 \%$ corresponding to the identification of all the optotypes.

\section{Statistical analysis}

Statistical analysis was performed using IBM SPSS 22.0 (SPSS Inc., Chicago, IL, USA). Shapiro-Wilk normality tests were performed to assess the applicability of nonparametric tests. Wilcoxon signed-rank test was used for comparing differences in each test between visits and Mann-Whitney between groups. A significance level of 0.05 ( $p$ value) was used for all statistical tests.

\section{Results}

There were 5 male and 5 female patients included in the study. Mean \pm SD age was $56.90 \pm 6.06$ years (range $49-70$ ) Table I shows the preoperative data.

\section{Visual outcomes}

The visual and refractive results were comparable 1 month and 12 months postoperatively, with no statistically significant differences observed (Tab. II).

\section{Contrast sensitivity}

The results of contrast sensitivity (expressed in $\mathrm{dB}$ ), over 6 different spatial frequencies, are depicted in Figure 3. As

TABLE I - Preoperative data of the enrolled subjects

\begin{tabular}{lc}
\hline & Mean \pm SD \\
\hline IOP, mm Hg & $14.3 \pm 1.92$ \\
UDVA, logMAR & $0.64 \pm 0.35$ \\
BCDVA, logMAR & $0.32 \pm 0.21$ \\
SE, D & $-0.57 \pm 0.28$ \\
AL, mm & $23.64 \pm 1.17$ \\
Specular microscopy, cells $/ \mathrm{mm}^{3}$ & $2587 \pm 352.31$ \\
Mean corneal K readings, D & $43.20 \pm 1.40$ \\
IOL power calculation, D & $20.05 \pm 3.12$ \\
\hline
\end{tabular}

$A L=$ axial length; $B C D V A$ = best-corrected distance visual acuity; $I O L=$ intraocular lens; $\mathrm{IOP}=$ intraocular pressure; $\mathrm{SE}=$ spherical equivalent; UDVA = uncorrected distance visual acuity; $\mathrm{D}=$ diopters.

TABLE II - Visual outcomes 1 month and 12 months postoperatively

\begin{tabular}{|c|c|c|c|c|c|c|c|c|}
\hline & \multicolumn{4}{|c|}{1 month postoperatively } & \multicolumn{4}{|c|}{12 months postoperatively } \\
\hline Distance & $0.00 \pm 0.01$ & $0.00 \pm 0.05$ & $-0.10 \pm 0.05$ & $-0.10 \pm 0.02$ & $0.00 \pm 0.08$ & $0.00 \pm 0.05$ & $-0.10 \pm 0.05$ & $-0.10 \pm 0.02$ \\
\hline Intermediate, $70 \mathrm{~cm}$ & $0.03 \pm 0.06$ & $0.03 \pm 0.04$ & $0.00 \pm 0.04$ & $0.00 \pm 0.02$ & $0.02 \pm 0.10$ & $0.00 \pm 0.06$ & $0.00 \pm 0.03$ & $0.00 \pm 0.02$ \\
\hline
\end{tabular}

DCVA = distance-corrected visual acuity; UDVA = uncorrected distance visual acuity; UVA = uncorrected visual acuity. Values are mean \pm SD (logMAR).

${ }^{a}$ No statistically significant differences ( $\left.p>0.05\right)$. 

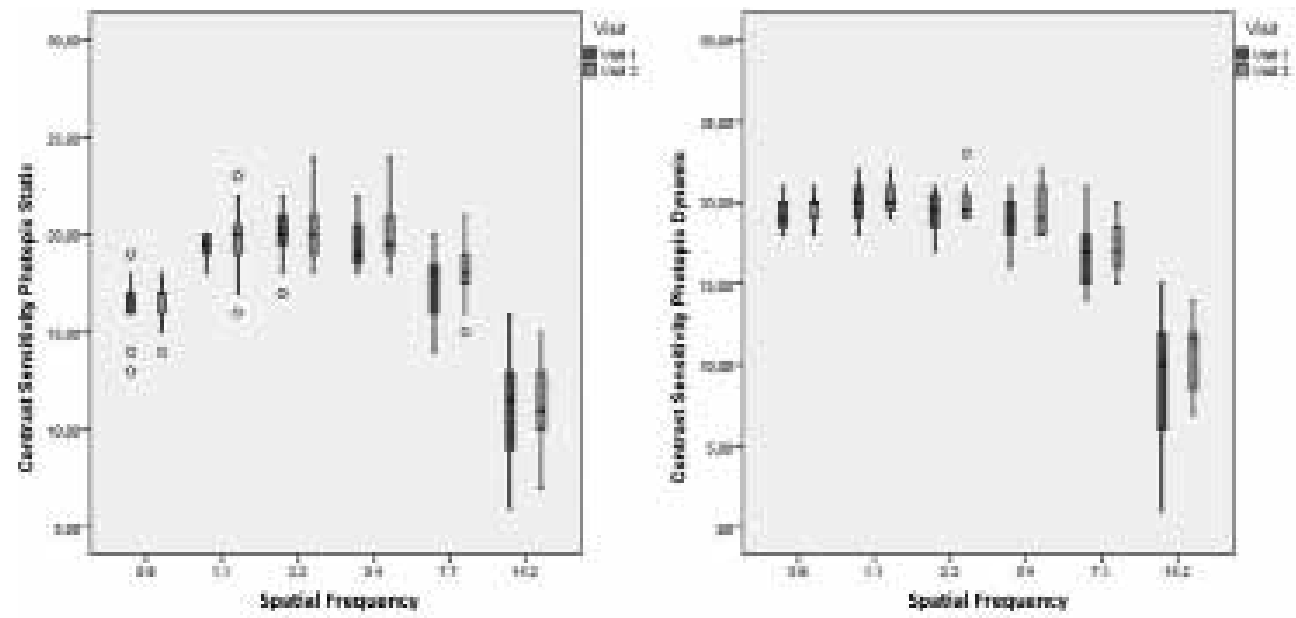

Fig. 3 - Contrast sensitivity (CS) box plot charts comparing the $1^{\text {st }}$ (visit 1) and $12^{\text {th }}$ (visit 2) postoperative months. The results of photopic $\left(80 \mathrm{~cd} / \mathrm{m}^{2}\right)$ and low mesopic $(0.08 \mathrm{~cd} /$ $\mathrm{m}^{2}$ ) contrast sensitivity testing under different spatial frequencies $(0.6$, $1.1,2.2,3.4,7.1$, and $14.2 \mathrm{cpd}$ ) are expressed in $\mathrm{dB}$, both for static (0 $\mathrm{Hz})$ and dynamic $(10 \mathrm{~Hz})$ conditions. There were no statistically significant differences between the first and last visit for any of the tested variables $(p>0.05)$.
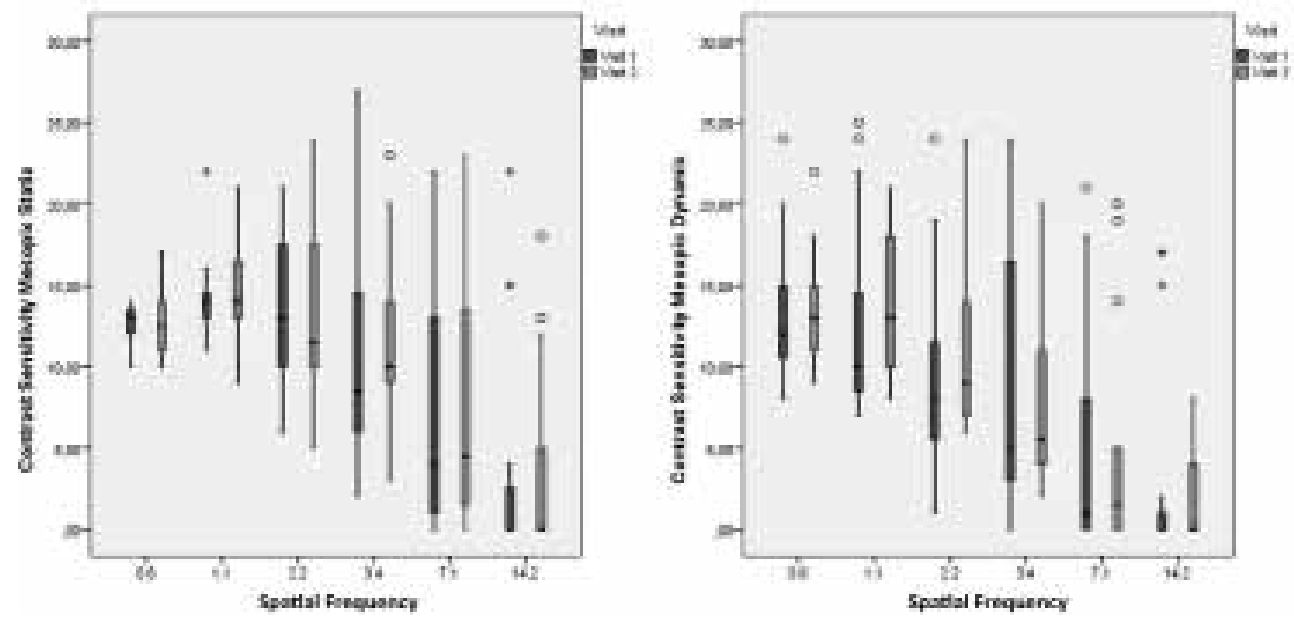

expected, lower contrast sensitivity values were found at low mesopic conditions when compared with photopic conditions. There were no statistically significant differences between the first and last visit $(p>0.05)$ for any of the testing conditions.

\section{Motion/speed, achromatic and chromatic contrast discrimination}

The results of the psychophysical tests used to evaluate motion/speed and achromatic and chromatic contrast discrimination were compared with an age-matched control group of 36 eyes (mean age $55.27 \pm 1.22$ years; range $48-72$ ). Patients included in the control group were all phakic. The results (in $\%$ s) over the horizontal meridian $\left(0^{\circ}\right.$, tested at $7.5^{\circ}$ of eccentricity), the vertical meridian $\left(90^{\circ}\right.$, tested at $10^{\circ}$ of eccentricity), and the oblique meridians $\left(45^{\circ}\right.$ and $135^{\circ}$, tested at $15^{\circ}$ of eccentricity) are depicted in Figure 4 . There were no statistically significant differences between the first and last visit ( $p>0.05)$ or between these and the results of the age-matched control group $(p>0.05)$ for any of the tested variables.

\section{Glare and pupillometry}

As shown in Table III, there were no statistically significant differences in vision under a glare source and pupillometry between the $1^{\text {st }}$ and $12^{\text {th }}$ postoperative months, even though there was a trend towards an increase in the number of identified optotypes 12 months postoperatively.

\section{Complications}

No significant IOL decentration was observed in any case at the slit-lamp examination. There were no cases of posterior capsular opacification or IOL opacification detected during follow-up. There were no cases of postoperative cystoid macular edema. Three patients mentioned halos and glare during night driving in the first postoperative month. However, this did not interfere with their daily life activities and improved during the course of follow-up.

\section{Discussion}

Multifocal IOL design has improved significantly in recent years. Although optimal distance and near VA can be easily achieved through a bifocal design, good levels of intermediate vision are often harder to attain (21). By assessing differences in optical performance of 9 multifocal IOLs using an optical bench, Gatinel and Houbrechts (12) demonstrated that the intermediate vision provided by bifocal IOLs is most closely related to the depth of field and that intermediate VA 

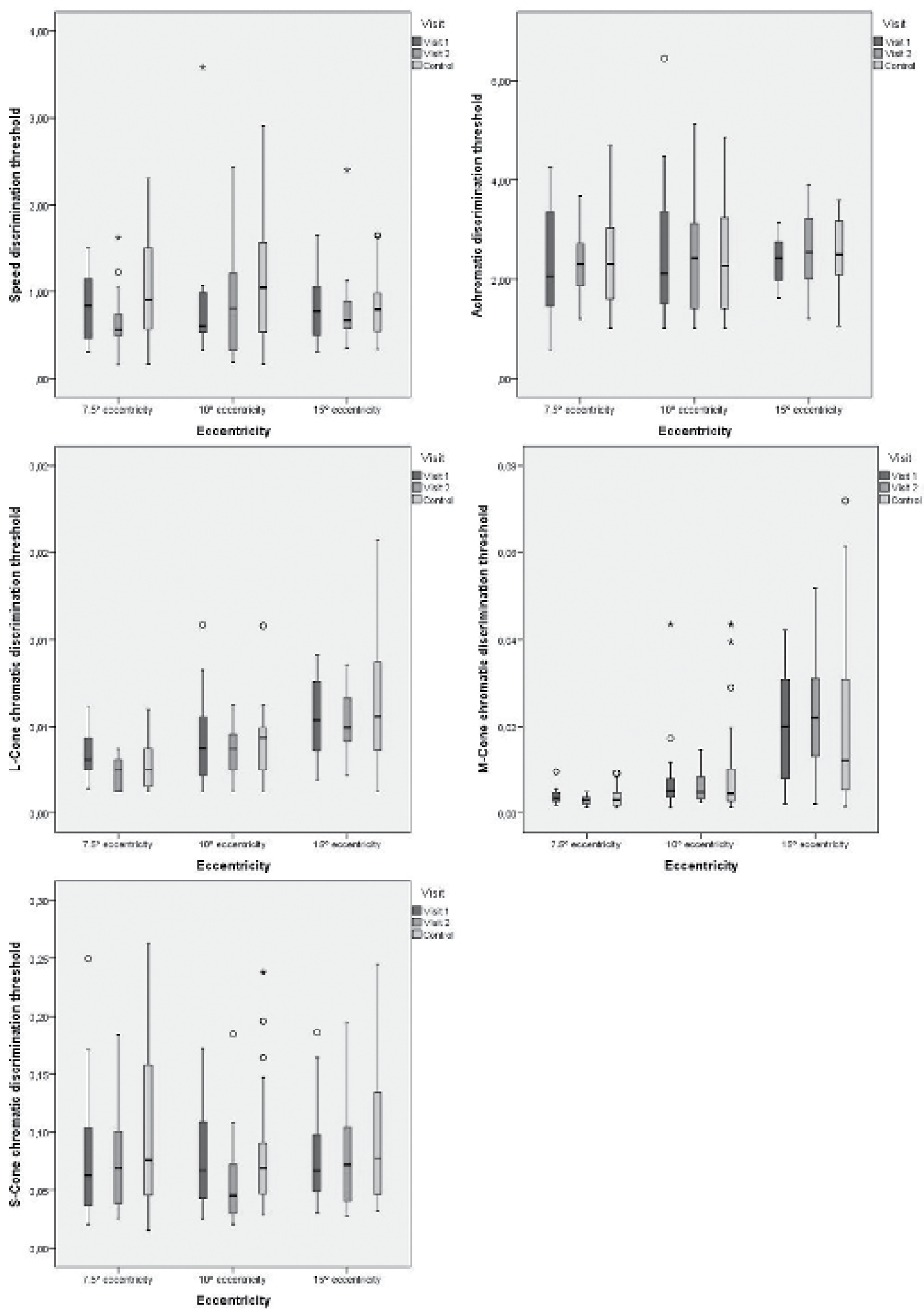

Fig. 4 - Motion/speed and achromatic and chromatic contrast discrimination results $(\% / \mathrm{s})$ over the horizontal $\left(0^{\circ}\right)$, vertical $\left(90^{\circ}\right)$, and oblique $\left(45^{\circ}\right.$ and $\left.135^{\circ}\right)$ meridians, tested at $7.5^{\circ}, 10^{\circ}$, and $15^{\circ}$ of eccentricity, respectively. There were no statistically significant differences between the $1^{\text {st }}$ (visit 1 ) and $12^{\text {th }}$ (visit 2) postoperative months or between these and the age-matched control group ( $\left.p>0.05\right)$. 
TABLE III - Glare and pupillometry

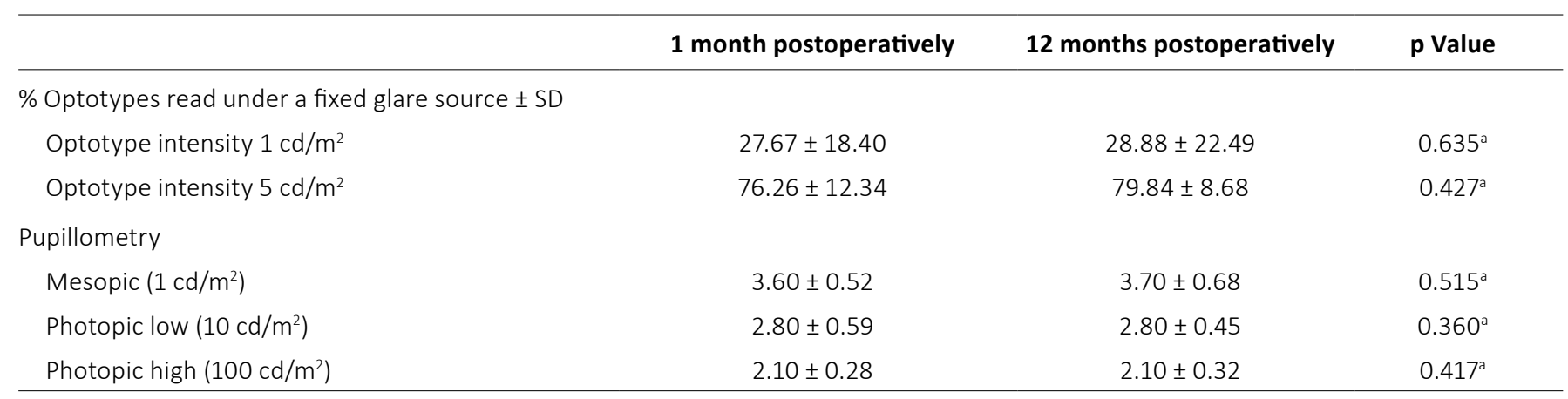

${ }^{a}$ No statistically significant differences.

could be improved with the existence of a third focal point. The introduction of trifocal IOL models was intended to address this particular issue. Several clinical studies $(5,13-15)$ have already evaluated the postoperative visual outcomes after bilateral implantation of the new FineVision ${ }^{\circledR}$ diffractive trifocal IOL and confirmed an extended range of clear uncorrected VA with this IOL model. In our study, mean monocular uncorrected distance VA (UDVA) was $0.00 \pm 0.08 \log$ MAR at 12 months. These results are slightly better than the ones reported by Sheppard et al (5) (UDVA $0.19 \pm 0.09$ at 2 months) and Alió et al (15) (UDVA $0.18 \pm 0.13$ at 6 months) but comparable to the outcomes of Cochener et al (13) (UDVA 0.08 \pm 0.12 at 6 months), the largest published report of FineVision ${ }^{\circledR}$ trifocal IOL found in the literature $(n=94)$. Monocular distance-corrected near VA (DCNVA) was $0.20 \pm 0.09 \log M A R$ in our population, a result that was worse than the ones reported by Alió et al (15) (DCNVA $0.16 \pm 0.13$ ) or Cochener et al (13) (DCNVA $0.08 \pm 0.08$ ). Although Sheppard et al (5) did not present the logMAR results of DCNVA, the authors used the NAVQ test (22) to evaluate subjective satisfaction with uncorrected near vision and report high levels of patient satisfaction in their 15-patient cohort.

Monocular distance-corrected intermediate VA (DCIVA) was $0.00 \pm 0.06 \log$ MAR in our cohort. Our results are similar to the ones reported by Cochener et al (13) (DCIVA $0.08 \pm$ $0.10)$, even though the authors used a Parinaud near visual chart at $65 \mathrm{~cm}$ to evaluate intermediate VA. The DCIVA results reported by Alió et al (15) were slightly worse (0.17 \pm 0.09$)$. It is likely that the differences in distance, near, and intermediate VA results can be explained by different methodologies of evaluation (namely the type of scale and the testing distance) and age differences between populations. Optical performance of the human eye is known to progressively decline with age (23), with a resultant reduction in VA for elderly phakic and pseudophakic individuals (24).

Even though VA testing is an important reflection of visual function, it conveys purely subjective results. Subjective data per se cannot adequately describe the performance and optical outcomes of a new IOL design. A quantitative evaluation of several parameters of visual function using computerized psychophysical tests can complement and thus reinforce the results of a subjective analysis. Using proprietary software, we were able to objectively assess contrast sensitivity, pupillometry, glare, chromatic and achromatic contrast discrimination, and motion discrimination. To our knowledge, this is the first study on FineVision ${ }^{\circledR}$ trifocal IOL that addresses these many aspects of visual function. The occurrence of photic phenomena (halos, glare, and positive dysphotopsia) and contrast sensitivity loss after bilateral multifocal IOL implantation are well-described in the literature and can affect quality of life (7). Even though contrast sensitivity testing in patients with bilateral implantation of this diffractive trifocal IOL was performed by Cochener et al (13) and Lesieur (14), both authors used letter charts with $25 \%$ and $10 \%$ contrast. Technical problems associated with letter charts include unevenness of illumination, fading of the print, reflections from the surface, and the need to recognize letters (25). Sheppard et al (5) and Alió et al (15) used computer-based contrast sensitivity testing but the first used luminance levels of $85 \mathrm{~cd} / \mathrm{m}^{2}$ (photopic conditions) and $5 \mathrm{~cd} / \mathrm{m}^{2}$ (mesopic conditions) and the latter used luminance levels of $3 \mathrm{~cd} / \mathrm{m}^{2}$ (mesopic conditions). In pupil-dependent IOL designs, low mesopic contrast sensitivity testing (luminance $0.08 \mathrm{~cd} / \mathrm{m}^{2}$ ) is particularly important since pupil dilation attenuates some of the advantages offered by the IOL (4). Also, complaints of decreased contrast sensitivity are usually elicited under dim light conditions (i.e., night driving), and a low value of luminance $\left(0.08 \mathrm{~cd} / \mathrm{m}^{2}\right)$ is more likely to represent a real-life mesopic scenario (16). Based on this, we tested contrast sensitivity under photopic $\left(80 \mathrm{~cd} / \mathrm{m}^{2}\right)$ and low mesopic $\left(0.08 \mathrm{~cd} / \mathrm{m}^{2}\right)$ settings. We used an objective, computer-based test (Metrovision ${ }^{\circledR}$ ). Advantages of computer testing include flexibility of programming to display contrast targets in a random pattern, alter the contrast between levels, and use a staircase strategy to bracket the contrast threshold (25). We found that contrast sensitivity results under photopic and low mesopic conditions were identical at the $1^{\text {st }}$ and $12^{\text {th }}$ postoperative month. Not surprisingly, contrast sensitivity proved better in a photopic setting than in low mesopic conditions. Globally, the satisfactory contrast sensitivity function observed in our population, even in a low mesopic setting, can be explained by the adequate light distribution of the FineVision ${ }^{\circledR}$ trifocal IOL at different pupil apertures, due to its $100 \%$ diffractive technology. Specifically, for a $4.5-\mathrm{mm}$ pupil aperture, only $9 \%$ of light energy reaches the intermediate focus, $25 \%$ reaches the near focus, and the other $67 \%$ of the light reaches the distance focus $(11,15)$. Since $2 / 3$ of 
light is directed for distance vision, contrast sensitivity is then preserved. The same software (Metrovision ${ }^{\circledR}$ ) was also used for pupillometry and halometry/glare testing. As expected, pupillometry was dependent on the luminance levels, with a mean pupil diameter of $3.7 \mathrm{~mm}, 2.8 \mathrm{~mm}$, and $2.1 \mathrm{~mm}$ under mesopic $\left(1 \mathrm{~cd} / \mathrm{m}^{2}\right)$, low photopic $\left(10 \mathrm{~cd} / \mathrm{m}^{2}\right)$, and high photopic $\left(100 \mathrm{~cd} / \mathrm{m}^{2}\right)$ settings, respectively. The glare test we used consists of recognizing letters on a screen in the presence of a light source at the side of the screen. Predictably, the intensity of the optotype presented to the patient (either $1 \mathrm{~cd} / \mathrm{m}^{2}$ or $5 \mathrm{~cd} / \mathrm{m}^{2}$ ) had a positive influence on the percentage of optotypes read under a fixed glare source. The performance attained by the FineVision ${ }^{\circledR}$ trifocal IOL renders this new IOL model a fairly good glare testing result. This IOL favors distance vision with a large pupil diameter to minimize halos or glare perception under mesopic conditions. This can be fulfilled due to an asymmetric distribution of energy among the 3 foci (near, intermediate, and far vision) (11). Sheppard et al (5) used halometry to measure the size of the glare area for each patient monocularly and binocularly under mesopic $\left(5 \mathrm{~cd} / \mathrm{m}^{2}\right)$ conditions. Since the test used in our cohort is different, the results cannot be properly compared.

To our knowledge, this is the first study using psychophysical tests to address motion discrimination and chromatic and achromatic contrast discrimination in patients who underwent bilateral implantation of FineVision ${ }^{\circledR}$ trifocal IOL. We used proprietary software to explore the effect produced by the IOL in these parameters and compared the results with an age-matched control group. The target threshold of discrimination in all these tests increased with the eccentricity of the stimulus. This is anticipated given the fact that the target is presented further from the fovea. We found no statistically significant differences between the first and last visit or between patients and the age-matched control group for the parameters tested (motion discrimination, chromatic and achromatic contrast discrimination). The goal of a quantitative test is to produce results that are repeatable upon retesting and are close to the patient's true score (25). Our results reinforce the functional stability of the $\mathrm{IOL}$ as soon as 1 month after surgery and suggest that the FineVision ${ }^{\circledR}$ trifocal IOL does not produce a significant change in color vision, in spite of its blue-blocking filter. According to Gatinel et al (11), this is because the FineVision ${ }^{\circledR}$ trifocal IOL does not block as much blue light as other IOL models, hence avoiding a negative effect on color perception.

Apart from the small number of included subjects, one important limitation of our study is the absence of a defocus curve. This, however, has been extensively reported by others (5, 13-15), and published data have consistently shown an extended range of clear vision rather than distinct peaks corresponding to the $+1.75 \mathrm{D}$ and $+3.50 \mathrm{D}$ adds. The prospective nature of our study, along with the innovative methodology, compensate for the aforementioned limitations.

\section{Conclusion}

An objective assessment of visual function through quantitative computerized psychophysical approaches allows for a precise and reproducible evaluation that significantly complements a purely subjective analysis. The Physiol FineVision ${ }^{\circledR}$ trifocal IOL provided a satisfactory full range of vision and quality of vision parameters 12 months after surgery.

\section{Disclosures}

Financial support: No financial support was received for this submission.

Conflict of interest: None of the authors has conflict of interest with this submission.

Meeting presentation: A preliminary version of this study was presented at the XXXII Congress of the ESCRS (FP-4050), London, UK, September 16, 2014.

\section{References}

1. Agresta B, Knorz MC, Kohnen T, Donatti C, Jackson D. Distance and near visual acuity improvement after implantation of multifocal intraocular lenses in cataract patients with presbyopia: a systematic review. J Refract Surg. 2012;28: 426-35.

2. Alfonso JF, Fernández-Vega L, Puchades C, Montés-Micó R. Intermediate visual function with different multifocal intraocular lens models. J Cataract Refract Surg. 2010;36:733-9.

3. Alio JL, Plaza-Puche AB, Javaloy J, Ayala MJ, Moreno LJ, Piñero DP. Comparison of a new refractive multifocal intraocular lens with an inferior segmental near add and a diffractive multifocal intraocular lens. Ophthalmology. 2012;119:555-63.

4. Rosa AM, Loureiro Silva MF, Lobo C, et al. Comparison of visual function after bilateral implantation of inferior sector-shaped near-addition and diffractive-refractive multifocal IOLs. J Cataract Refract Surg. 2013;39:1653-9.

5. Sheppard AL, Shah S, Bhatt U, Bhogal G, Wolffsohn JS. Visual outcomes and subjective experience after bilateral implantation of a new diffractive trifocal intraocular lens. J Cataract Refract Surg. 2013;39:343-9.

6. Cillino G, Casuccio A, Pasti M, Bono V, Mencucci R, Cillino S. Working-age cataract patients: visual results, reading performance, and quality of life with three diffractive multifocal intraocular lenses. Ophthalmology. 2014;121:34-44.

7. de Vries NE, Nuijts RM. Multifocal intraocular lenses in cataract surgery: literature review of benefits and side effects. J Cataract Refract Surg. 2013;39:268-78.

8. Shimizu K, Ito M. Dissatisfaction after bilateral multifocal intraocular lens implantation: an electrophysiology study. J Refract Surg. 2011;27:309-12.

9. de Vries NE, Webers CA, Touwslager WR, et al. Dissatisfaction after implantation of multifocal intraocular lenses. J Cataract Refract Surg. 2011;37:859-65.

10. Woodward MA, Randleman JB, Stulting RD. Dissatisfaction after multifocal intraocular lens implantation. J Cataract Refract Surg. 2009;35:992-7.

11. Gatinel D, Pagnoulle C, Houbrechts Y, Gobin L. Design and qualification of a diffractive trifocal optical profile for intraocular lenses. J Cataract Refract Surg. 2011;37:2060-7.

12. Gatinel D, Houbrechts Y. Comparison of bifocal and trifocal diffractive and refractive intraocular lenses using an optical bench. J Cataract Refract Surg. 2013;39:1093-9.

13. Cochener B, Vryghem J, Rozot $P$, et al. Visual and refractive outcomes after implantation of a fully diffractive trifocal lens. Clin Ophthalmol. 2012;6:1421-7.

14. Lesieur G. [Outcomes after implantation of a trifocal diffractive IOL.] J Fr Ophtalmol. 2012;35:338-42.

15. Alió JL, Montalbán R, Peña-García P, Soria FA, Vega-Estrada A. Visual outcomes of a trifocal aspheric diffractive intraocular lens with microincision cataract surgery. J Refract Surg. 2013;29:756-61. 
16. Eloholma M, Ketomaki J, Orrevetelainen P, Halonen L. Visual performance in night-time driving conditions. Ophthalmic \& physiological optics. J British Coll Ophthalmic Opticians. 2006; 26:254-63.

17. Hietanen MA, Crowder NA, Ibbotson MR. Differential changes in human perception of speed due to motion adaptation. J Vis. 2008;8:1-10.

18. Retzlaff JA, Sanders DR, Kraff MC. Development of the SRK/T intraocular lens implant power calculation formula. J Cataract Refract Surg. 1990;16:333-40.

19. Castelo-Branco M, Faria P, Forjaz V, Kozak LR, Azevedo H. Simultaneous comparison of relative damage to chromatic pathways in ocular hypertension and glaucoma: correlation with clinical measures. Invest Ophthalmol Vis Sci. 2004;45: 499-505.

20. Stone MC. Representing colors as three numbers. IEEE Comput Graph Appl. 2005;25:78-85.
21. Mojzis P, Peña-García P, Liehneova I, Ziak P, Alió JL. Outcomes of a new diffractive trifocal intraocular lens. J Cataract Refract Surg. 2014;40:60-9.

22. Buckhurst PJ, Wolffsohn JS, Gupta N, Naroo SA, Davies LN, Shah S. Development of a questionnaire to assess the relative subjective benefits of presbyopia correction. J Cataract Refract Surg. 2012;38:74-9.

23. Guirao A, González C, Redondo M, Geraghty E, Norrby S, Artal $P$. Average optical performance of the human eye as a function of age in a normal population. Invest Ophthalmol Vis Sci. 1999;40:203-13.

24. Westcott MC, Tuft SJ, Minassian DC. Effect of age on visual outcome following cataract extraction. Br J Ophthalmol. 2000; 84:1380-2.

25. Richman J, Spaeth GL, Wirostko B. Contrast sensitivity basics and a critique of currently available tests. J Cataract Refract Surg. 2013;39:1100-6. 